\title{
Denuncias poéticas: la lamentación de Fray Calixto de San José Túpac Inca y su discurso bajtiniano con doble voz ${ }^{*}$
}

\author{
Cody Hanson ${ }^{1}$ \\ Indiana State University (EE.UU.)
}

\section{Resumen}

El presente artículo explora la "Representación Verdadera", una carta de 1748 que se atribuye a Fray Calixto de San José Túpac Inca, un fraile mestizo de las sierras peruanas. La carta, que se dirige al Rey Fernando VI de España, protesta sobre el tratamiento inhumano que padecen los indios andinos y su exclusión sistemática al no ser considerados como miembros en completa hermandad dentro de los órdenes religiosos. Los indios podían solamente ser donados en las órdenes y trabajar como sirvientes, sin la posibilidad de ser elevados. Este mismo tipo de tratamiento se extendía en todos los aspectos de la sociedad colonial. En su carta, Fray Calixto utiliza el poema encontrado en el libro Lamentaciones, capítulo V, como

\begin{abstract}
This paper explores "Representacion Verdadera", a letter allegedly written by Fray Calixto de San José Túpac Inca in 1748, a mestizo friar from the Peruvian highlands. The letter, which is addressed to King Ferdinand VI of Spain, shows a protest for the inhuman treatment that the Andean natives suffered and how their systematic exclusion in their religious orders occurred, as they were not considered part of the brotherhood system. The natives could only be "donated" to the religious orders and work as servants. This type of treatment was extended to all aspects of colonial society. In his letter, Fray Calixto uses the poem found in the book of Lamentations, chapter $\mathrm{V}$, as the framework in which the complaints of the ab-
\end{abstract}

\footnotetext{
* "Poetical denounce: The lamentation by Fray Calixto de San José Túpac Inca and its Bakhtinian double-voiced discourse"

Recibido: 30 de septiembre de 2013 - Aprobado: 25 de octubre de 2013

1 Doctor en Spanish American Literature de Purdue University (Indiana) y Master of Arts of Brigham Young University (Provo, Utah). Bachelor of Arts, Modern Languages and Literatures del California Polytechnic State University (San Luis Obispo, California).e-mail: codychanson@gmail.com
} 
el marco en que numera las quejas de los indios, conectando sus aflicciones con las del antiguo pueblo de Israel. El franciscano crea un tipo de discurso bajtiniano con doble voz que hábilmente combina varias voces para crear paralelos entre diferentes situaciones históricas y sociales.

Palabras clave: indios, carta, lamentación, dialogismo, discurso con doble voz. origines connects them with the affliction of the ancient people of Israel. The Franciscan creates a type of bakthinian discourse with a dual voice that skilfully combines several voices to create parallels between different historic and social situations.

Keywords: indigenous people, letter, lamentation, dialogism, double-voiced discourse.

El padre mestizo Fray Calixto de San José Túpac Inca nació en las sierras andinas, alrededor de 1710, hijo legítimo de un español, Pedro Montes, y de Dominga Estefanía Túpac Inca, princesa indígena descendiente de Túpac Inca Yupanqui. Asumió el sacerdocio en 1727 y se convirtió en un valioso miembro de la Orden Franciscana a causa de su inteligencia, virtud, y especialmente por su profundo conocimiento de los idiomas autóctonos del Perú, pudiendo evangelizar a los indios en regiones apartadas. Esta experiencia de trabajar con los indios del virreinato lo dejaría plenamente convencido de que las autoridades españolas locales jamás tratarían justamente a los quechua. A fin de cambiar esta deplorable situación, Fray Calixto decidió servir como vocero de aquellos que habían sido rotundamente silenciados, y una de las formas en que lo hizo fue mediante una carta dirigida al rey Fernando VI de España (Loayza, 1948: 1-3).

Bernales (1969) describe el carácter obstinado del dedicado religioso: "Sus afanes, casi odiseas, nos muestran un carácter susceptible, inquieto y tenaz, agudizado todo por un comprobado criticismo" (5). Así, pues, la carta que Fray Calixto produjo en 1748 utilizaría el quinto poema del libro de Lamentaciones del Antiguo Testamento, para comparar el sufrimiento de los judíos con los agravios cometidos en contra de los indios peruanos ${ }^{2}$. El fraile cuestiona el hecho de que los

\footnotetext{
${ }^{2}$ La carta se titula: "Representación verdadera y exclamación rendida y lamentable que toda la nación indiana hace a la Majestad del Señor Rey de las Españas y Emperador de las Indias, el Señor Don Fernando VI, pidiendo los atienda y redima, sacándolos del afrentoso vituperio y oprobio en que están más de doscientos años
} 
indios hayan sido subvalorados y ofrece soluciones para relevar la tensión que este injusto sometimiento causa, asegurando que el rey Fernando VI tiene la santa responsabilidad de enmendar la situación en Perú. Por lo demás, la manera casi "fantástica" en que la carta fue entregada a las manos mismas de su Majestad contribuye a su valor "mítico".

Fray Calixto redactó su carta en consultación y en conjunto con el cabildo de Lima y con los caciques de varias regiones del Perú, quienes le otorgaron su autorización para representarlos ante la Corte Real y "denunciar el estado de injusticias y de descontento que cada día se extendía más en el pueblo peruano” (Prieto, 1974: 128). Es probable, igualmente, que la carta se escribiera con la aportación de otros francisanos íntimamente conectados con su historia y afines a sus ideas ${ }^{3}$. No obstante, fue Fray Calixto quien asumió la responsabilidad y expuso su vida y su carrera religiosa, a fin de ver la carta en las manos del Rey. Producida en un periodo tumultuoso, cuando era difícil gobernar y mejorar la situación en Lima, debido a la destrucción del terremoto de 1746, su insatisfacción general y su denuncia contra la exclusión sistemática de los indios de las órdenes religiosas podía llegar a ser "improcedente", a pesar de que su clamor explícito por un cambio social no tenía como objetivo romper lazos con la monarquía, sino más bien afirmar su lealtad a la corona.

El pueblo por aquellos días expresaba abiertamente su descontento con las autoridades peninsulares, especialmente ante sus renovados esfuerzos por gobernar estrictamente y recolectar impuestos. Walker (2008) anota que entre 1735 y 1747 hubo más de doce revueltas en contra de las autoridades virreinales (163). La rebelión de Juan Santos Atahualpa llevaba ya varios años en marcha cuando la carta de Fray Calixto salió a luz. El resentimiento de los indios, por lo demás, habría de manifestarse más tarde con la rebelión de Huarochirí, en 1750, y luego con la rebelión de Tupac Amaru II, en

- Exclamación de los indios americanos usando para ella de la misma que hizo el profeta Jeremías a Dios en el capítulo 5 y último de sus Lamentaciones".

${ }^{3}$ Hay cierta ambigüedad en cuanto a la autoría de la carta. Bernales (1969) concluye que Fray Antonio Garro fue el autor y que Fray Calixto el que la presentó al rey, "llevando a manos del rey el manifiesto escrito imprudentemente por Fr. Antonio Carro" (12). Walker (2008) también reconoce el problema de la autoría y sugiere que otro posible autor es Fray Isidoro de Cala y Ortega (66). Leinhard (1992), por su parte, opta por una conclusión más diplomática: “¿Es el hermano Calixto el autor de la 'Exclamación'? En una carta al rey español, el virrey del Perú, Conde de Superunda, la atribuiría, varios años más tarde (15 de enero de 1757), al franciscano P. Antonio Garro. Si bien no se conoce definitivamente la identidad de su autor, se puede afirmar que fray Calixto terminó haciéndola suya" (240). 
1780. En todo caso, el fraile partió de Lima con la carta en 1748 y viajó por muchos pueblos, hasta llegar a la capital incaica en noviembre del mismo año, donde sin éxito intentó persuadir a otros caciques a unirse a la causa y aportar con una limosna (Loayza, 1948: 59). Debido a que realizó su viaje sin la aprobación de sus superiores, y sin permiso legal para viajar a España, tuvo que emprender un largo viaje, dificultoso y accidentado, por Cuzco, Buenos Aires, Río de Janeiro, Lisboa y Roma, para llegar finalmente a Madrid el 22 de agosto de 1750 (Vargas, 1956: 244; Loayza, 1948: 49-53).

Fray Calixto describe: "no pude comer ni dormir por los vómitos tan repetidos que padecí; y el mayor vómito que me atravesaba el alma era el no tener plata" (Loayza, 1948: 51). Viajó con un compañero, el misionero francisano Isidoro de Cala y Ortega, pero sin dinero. Por lo tanto, tuvieron que depender de la misericordia ajena, y cuando la caridad y la limosna faltaron, debieron endeudarse con más de 600 pesos -los cuales más tarde, dirigiéndose al cabildo de Lima, implorarían cancelar-. (Loayza, 1948: 59). Cuando alcanzaron finalmente Madrid, el fraile y su compañero procuraron una audiencia inmediata con el Rey; no obstante, la Corte Real les aseguró que no sería tan fácil. De modo que los misioneros decidieron encontrarse con el Rey por estratagema y marcharon al día siguiente al campo, donde sabían que Su Majestad iría a cazar. Según el osado fraile: "Y aunque nos habían ponderado mucho la mucha dificultad que había en ver al Rey y poderle hablar; no obstante, a costa de riesgos y peligros, aun de la propia vida, le salimos al encuentro; metiéndonos por entre la chusma de soldados, y le entregamos a su Majestad (es de advertir que no paró la carroza de su Majestad, sólo sacó la cabeza por dos veces) nuestro escrito, dicho día 23" (Loayza, 1948: 53).

Como otros documentos oficiales de la época dirigidos al Rey, la carta exclamatoria adopta un tono formal que se caracteriza como una voz distinta a la voz que el autor asumiría bajo otros contextos. Mijaíl Bajtín (1981), en "Discourse in the Novel", afirma que cuando los seres humanos comunican, la mayoría de sus palabras son palabras tomadas de otros: "In all areas of life and ideological activity, our speech is filled to overflowing with other people's words, which are transmitted with highly varied degrees of accuracy and impartiality" (337). Aunque la carta reprocha al Rey su indiferencia hacia el pueblo indígena, continúa honrándole con todos los respetos requeridos cuando menciona su real nombre. Como es costumbre, la portada del documento menciona la grandeza del Rey y lo incluye como parte del título: "la Majestad del Señor Rey de las Españas y Emperador de las Indias, El Señor Don Fernando VI" (Loayza, 1948: 5). Y para señalarlo, dice: “Vos, Señor. ¡oh, Rey! ¡Oh, Monarca nuestro, español! 
¡Oh, Don Fernando, el católico, el piadoso, el deseado!” (Loayza, 1948, p. 24-25).

El usar las palabras de otros, a fin de expresarse, es una práctica muy común: "in the everyday speech of any person living in society, no less than half (on the average) of all the words uttered by him will be someone else's words (consciously someone else's), transmitted with varying degrees of precision and impartiality" (Bajtín, 1981: 339). Las personas utilizan las palabras de otros y las alteran para ajustarlas a un nuevo contexto. Así, pues, no nos debe sorprender que el religioso escoja un poema de la Santa Biblia para validar y promover su argumento. El uso de las palabras de los profetas aquellos que comunican la palabra y la voluntad de Dios- sirve para investir sus propias palabras de una autoridad divina, justificando los medios y la urgencia que Fray Calixto emplea para escribir su carta y entregarla en las manos del Rey. Según Kee (1997), en The Cambridge Companion to the Bible, el paralelismo es una característica esencial de la antigua poesía hebraica.

El paralelismo sinónimo, uno de los tres tipos tradicionales, "repeats the same thing, or almost the same sense in a second line using different words from the first line" (237).

En el caso del quinto capítulo de Lamentaciones (Reina Valera 1960), está formado por veintidós estrofas de dos líneas cada una, y utiliza el paralelismo sinónimo. La primera presenta una idea (generalmente una queja) y la segunda la expande con palabras distintas que transmiten esencialmente lo mismo: "Acuérdate, oh Jehová, de lo que nos ha sucedido;/ Mira, y ve nuestro oprobio" (V, v. 1). En la primera línea del poema judaico, el autor ruega que Dios tenga presente los recientes acontecimientos de su pueblo, y en la segunda, repite el mandato "acuérdate" de la primera línea con el mando "mira", y clarifica que no son solamente sucesos, sino acontecimientos de oprobio, y de hecho "the greatest tragedy that Israel has yet experienced" (Myers, 1987, 639). El uso de la repetición, así mismo, amplifica la fuerza del mensaje lamentador y refleja la actitud típica de un quejoso que no puede ver más allá del sufrimiento.

Al dar voz a numerosos lamentos, Fray Calixto inicia con las palabras de las Sagradas Escrituras, y después explica cómo se aplican al pueblo indígena, para así exponer metódicamente los agravios cometidos en su contra. El religioso manipula el contexto en que el poema se encuentra, enfatizando “the brute materiality of another's words" (Bajtín, 1981: 340). El poema sirve como el marco que Fray Calixto emplea para dar orden a sus argumentos. Esta manera de 
usar el poema bíblico crea un doble paralelismo, un discurso con doble voz, pues no sólo hay un eco entre la primera línea y la segunda de cada estrofa, como lo hay en la poesía hebrea, sino que también encima de cada estrofa se coloca un nivel adicional de paralelismo sinónimo que sitúa la estrofa dentro del contexto latinoamericano.

Después del largo título, la carta de Fray Calixto inicia con un epígrafe en latín del quinto capítulo de Lamentaciones. Al explicar la línea citada, inmediatamente declara que no está implorándole a Dios, sino al Rey Fernando VI: “¡Oh, Señor! ¡Oh, Monarca Católico! ¡Oh Emperador de las indias piadoso, muy católico y muy cristiano!” (Loayza, 1948: 7) Entonces, se repiten los versículos bíblicos en el idioma vulgar y los ponen en el contexto peruano. Freedman (1992), en The Anchor Bible Dictionary, explica que el poema inserto en Lamentaciones "expresses the historical experience of a community more than the personal experiences or opinions of one individual" (138). En este mismo espíritu, el poeta-fraile exclama por todos los indios americanos: "acordaos ya de lo que nos ha sucedido en más de dos siglos de oprobios! [...] Y nuestro pueblo cristiano, indiano, os clama llorando" (Loayza, 1948: 7). En vez de dirigir su lamento a Jehová, como el texto sagrado, pone al Rey de España en el mismo lugar supremo y venerable que Dios ocupa. El Dios de Israel tiene poder para afligir o salvar a su pueblo, alterando su destino; de igual forma, el Fernando VI tiene poder sobre sus vulnerables vasallos indios.

Fray Calixto continúa el paralelismo establecido entre el estado del pueblo de Israel y el pueblo indiano, presentando veintidós lamentos del pueblo peruano, que corresponden a las veintidós estrofas del poema bíblico. Cada lamento inicia siguiendo el mismo patrón: primero, cita la correspondiente escritura en latín y después la traduce al castellano, poniéndola en el contexto del pueblo indígena. Vemos así cómo principia su tercera queja: "Pupilli facti sumus absque patre", que se traduce como: "Somos pupilos y huérfanos sin padre" (Loayza, 1948: 8). El fraile afirma que el Rey Fernando VI es el padre del pueblo indígena y contextualiza la escritura con la siguiente pregunta y declaración acusatoria: “¿dónde está la honra para vuestros hijos, y tales hijos obedientes, rendidos, manos y humildes? No parece que tenemos padre tal" (Loayza, 1948: 8).

Aunque el Rey es el padre de los indios, según el fraile, no se comporta como tal, porque les ha abandonado como un padre que abandona a un huérfano, no habiendo honra en ser obedientes a él. El religioso mestizo, sin embargo, no sugiere una revolución: no quiere romper los lazos que unen el Perú con España, puesto que un 
hijo no puede divorciarse de su padre (Vargas, 1956: 247). Reafirma repetidamente su amor y fidelidad a la Corona, tal como un hijo pequeño que siempre se sujeta a su padre, aunque sea de mala gana. El uso de las palabras del profeta Jeremías sirve para suavizar su crítica del Rey y le permiten señalar a los representantes del Rey en el "Nuevo Mundo" como los verdaderos culpables de las quejas. Dueañas (2010) explica:

The use of Jeremiah here softens the criticism of the monarch for overlooking the plight of his Indian subjects. Since the king and his officials failed to provide the expected protection to Andean subjects, they behaved as tyrants. Andean writers, however, were usually cautious and launched subtle attacks against a distant crown, only to follow them with anxious insistence that he was not responsible for the "tyranny" of his representatives in Peru (118).

El humilde fraile sólo quiere recalcar que el Rey Fernando VI ha ignorado su deber con las Indias Occidentales y esto ha causado que los españoles del "Nuevo Mundo" maltraten a los indios andinos. Ya que critica el gobierno del Rey, el fraile hace grandes esfuerzos para afirmar su lealtad a la corona. Bernales (1969) sostiene que el hermano Calixto demostraba "en todo tiempo fidelidad a la Iglesia y a la Monarquía" (6). Por ejemplo, cuando escribe: "Vos pues, Señor, os repetimos: eternizaréis vuestro glorioso nombre, apartando de nosotros este oprobio" (Loayza, 1948: 25). Al dar oído a los indios americanos y restituirlos a su lugar, el Rey enaltecerá su nombre eternamente y cumplirá así con sus olvidados deberes paternales. La sexta queja que nombra, por otra parte, corresponde al sexto versículo del poema bíblico y le permite conectarse con el antiguo pueblo y así unir las dos experiencias: "parece que nos dominan egipcios y no españoles; que nos sujetan Faraones y no Reyes católicos" (Loayza, 1948: 10).

El fraile opina que el desperdicio que están sufriendo es el mismo que el pueblo judío padecía antiguamente, pues Fray Calixto, al igual que el autor de Lamentaciones, "grieves for the wretched state of his people, and prays that God remove Sion's reproach" (Steinmueller, 1956: 547). A través de la comparación, critica fuertemente al Rey de España, pues le dice que en vez de comportarse como un buen católico, actúa más bien como un rey pagano, como lo fueron los faraones. Más adelante, la carta arremete otra vez contra el gobierno del virreinato, que el Rey ha nombrado. Fray Calixto sugiere que el Rey puede asegurar el justo tratamiento del pueblo americano si nombra autoridades que obedezcan las leyes reales. Bernales (1969) 
comenta: "Su presencia en la corte de España, deja oír la voz del indio ante la monarquía misma, despreciando a las autoridades virreinales por considerarles que no eran representativas del gobierno español y anticipándose unos años el movimiento reformista americano" (5). Esta queja compara las autoridades regionales con gobernadores gentiles: "aun los españoles cristianos que vivían entre los moros, no eran tan abominados por ellos, como los Indios por los españoles, siendo cristianos y muy católicos" (Loayza, 1948: 40). Las autoridades virreinales son tan deplorables, porque, aunque los indios son buenos cristianos, no los tratan como sus hermanos en la fe. Aun los moros, que no compartían la fe cristiana, trataban a los españoles cristianos con más dignidad. A menos que el Rey se arrepienta e intervenga para cambiar esta situación, se puede deducir que el fraile espera que sufra las mismas calamidades que recayeron sobre faraón cuando Moisés liberó a los hijos de Israel, o las que cayeron sobre los moros en España, en 1492. Tal vez, por inferencia, el fraile se ve como un Moisés moderno, quien agoniza y aboga por la libertad de su pueblo. No obstante, nunca sugiere que este pueblo quiere algo más que ser tratado igual a todos los súbitos españoles.

Los indios reconocen que, aunque sean súbitos a la Corona, no tienen los mismos derechos que los mismos naturales de España. Envían la "Representación verdadera y exclamación rendida" a fin de apelar a su estado de inferioridad y exigir la devolución de su "puesto" como parte de la herencia del Rey Fernando. La Biblia exclama: "Nuestra heredad ha pasado a extraños, Nuestras casas a forasteros" ( $\mathrm{Lm}$. V, v.2). Este lamento expresado, según The Cambridge Companion to the Bible, "is one of the most poignant descriptions of the plight of an oppressed people anywhere in the Bible" (Kee, 1997: 262). La manifestación de opresión que hace el lamento peticiona por un cambio. Los indios profesan que, como vasallos del rey, son también su herencia: "somos vuestra herencia, somos vuestra casa" (Loayza, 1948: 7). La herencia del rey ha sido apoderada por "extranjeros y extraños", puesto que son los españoles quienes viven separados y segregados de los indios y "ocupan todos los pueblos, dignidades, judicaturas, así eclesiásticas como seculares" (Loayza, 1948: 7).

El fraile explica así que el rey ha permitido que su herencia y su casa fueran llevadas por extraños, tal como los hebreos fueron llevados cautivos por Babilonia, y le ruega que reclame lo suyo. Siguiendo el ejemplo establecido en Lamentaciones, Fray Calixto "describe vividly their plight and its causes and petition God for restoration" (Myers, 1987: 639). Se percibe, pues, una obvia repetición de acontecimientos entre ambas historias. El poema de Lamentaciones, como Freedman 
(1992) nota, en The Anchor Bible Dictionary, "give vivid short pictures of the horrors of the siege and its aftermath, reflect on the causes of the calamity, and appeal for mercy to the God who brought about the ruin of his own city and temple" (137). Del mismo modo, Fray Calixto redacta el angustioso tratamiento aguantado por su pueblo y su origen, a fin de convencerle al rey de que tenga misericordia de su pueblo.

El poema provee al fraile de las herramientas y argumentos necesarios para enfrentar los obstáculos establecidos por la opresión, recordándole que, tal como el pueblo de Israel, también ellos podrán sacudir las cadenas de Babilonia, para ganar la libertad después de haber pasado por el fuego purificador. El uso del poema de Lamentaciones sugiere que el sufrimiento del pueblo peruano se acabará con la ayuda y misericordia del poder real, tal como los judíos se libraron gracias a la compasión divina. El fenómeno de múltiples voces que interactúan y se unen para crear diálogo está claramente definido por Mijaíl Bajtín (1981), cuando estudia el "dialogismo" como elemento estilístico esencial del género de la novela e ilumina su rol en la creación del arte verbal. El estudio bajtiniano sobre el discurso revela que en una novela hay varias voces en juego, y sus observaciones y principios, por extensión, pueden aplicarse a otros textos con las mismas características, sean novelas o no.

Bajtín expone que hay una gran variedad de enunciados en el género de la novela, expresándose mediante muchas voces individuales temas e ideas. Estas voces se multiplican en muchas interrelaciones sociales. Para el teórico y crítico ruso, la característica básica de la novella -y de textos parecidos- es el dialogismo, que resulta de "links and interrelationships between utterances and languages, this movement of the theme through different languages and speech types, its dispersion into the rivulets and droplets of social heteroglossia" (263). Las distintas conexiones y voces que se forman para expresar el tema y el drama son una característica básica de textos novelísticos. Los avances bajtinianos en el discurso literario sirven para explorar los aspectos artísticos de las voces en la carta exclamatoria de Fray Calixto de San José Tupac Inca.

En la carta exclamatoria existe una fusión de dos géneros distintos. Fray Calixto incorpora un poema en su prosa expositiva, y efectivamente revuelve estos dos estilos de expresión escrita. Bajtín enseña la diferencia que hay entre el lenguaje de una obra poética y una obra en prosa. El poeta experimenta todo mediante un lenguaje interno, lo cual implica que no requiere el uso de otros lenguajes exteriores para expresarse. Por lo tanto, no es posible 
dudar del lenguaje de la poesía, aunque sí es permisible cuestionar las contradicciones, conflictos y dudas que surgen en el contenido de la obra. Estas dudas, no obstante, jamás afectan el lenguaje mismo (Bajtín, 1981: 286). Como el ruso explica: "Even when speaking of alien things, the poet speaks in his own language. To shed light on an alien world, he never resorts to an alien language, even though it might in fact be more adequate to that world. Whereas the writer of prose, by contrast -as we shall see- attempts to talk about his own world in an alien language" (287).

En otras palabras, el lenguaje de la poesía es personal y único. El propósito de un poema reside expresamente en su expresión: el poeta está ligado al lenguaje que su conciencia poética y artística produce. Por eso Bajtín sostiene que "the artificially created language of poetry must be directly intentional language, unitary and singular" (287). Ya que el religioso utiliza un lenguaje poético para transmitir su mensaje, las palabras de la carta llegan a ser incuestionables y autoritarias. El lenguaje de la prosa, en cambio, es un lenguaje social que redacta lo que el autor quiere expresar con un lenguaje que no le pertenece: su aspecto artístico es el resultado de un discurso con múltiples voces. El poema del quinto capítulo de Lamentaciones, por ejemplo, es sumamente descriptivo, con emociones fuertes que expresan la totalidad del mensaje en una sola voz poética. La "Representación verdadera", por su parte, aplica numerosas voces; se dirige al Rey Fernando VI con el lenguaje apropiado; sigue el estilo establecido de la época para documentos oficiales; utiliza las palabras poéticas de la Biblia en latín y español; emplea retórica; critica y alaba; es prosa y poesía; es la expresión de Fray Calixto, el cabildo de Lima y otros; y enumera los agravios con una voz, y ofrece sus correspondientes soluciones con otra.

El tipo de discurso en que hay varias voces es lo que Bajtín llama "heteroglossia", definiéndola como: "another's speech in another's language, serving to express authorial intentions but in a refracted way. Such speech constitutes a special type of double-voiced discourse [...] In such discourse there are two voices, two meanings and two expressions" ([sic.] 324). En su carta, Fray Calixto asume la voz de Lamentaciones para expresar sus propios agravios, modificando el significado del discurso hebraico. Aun así, el significado original del poema todavía sigue existiendo. La tensión entre las dos voces, y las imágenes que el misionero expone con el propósito de interrelacionar el verso bíblico con su experiencia, crea un texto altamente poético e ilustrativo. Como explica Bajtín, "these two voices are dialogically interrelated, they-as it were-know about each other [...] as if they actually hold a conversation with each other" 
(324). Hay un paralelismo fundamental, como ya hemos explorado, entre las lamentaciones bíblicas y las acusaciones clamadas por Fray Calixto. Y aunque muchas de sus quejas coinciden con el angustioso sentimiento encontrado en Lamentaciones, también debemos aclarar que muchas veces la conexión entre los textos es menos obvia.

En la carta las dos voces se manifiestan como un diálogo, donde el poema de Lamentaciones enumera sus aflicciones y la "Representación verdadera" responde con sus agravios que expresa con mayor severidad. El verso cuatro del poema reza: "Nuestra agua bebemos por dinero; Compramos nuestra leña por precio" (Lm., V, v.4). En estos primeros cuatro versos el poeta afligido registra en su propia voz todo lo que el pueblo de Israel ha perdido al ser llevado a una tierra extraña: su herencia, sus casas, sus padres y madres, e incluso los bienes como el agua y la leña que la tierra provee naturalmente. Mientras los judíos fueron arrastrados a otra tierra, los indios peruanos permanecieron en su país, pero ya no como dueños de él. Es por eso que la "Representación verdadera" entregada a Fernando VI ofrece una interpretación distinta dentro del contexto peruano. Según Fray Calixto, el agua y la leña que ellos han perdido es de otro tipo.

Fray Calixto, quien habla en primera persona del plural, observa: "bebemos nuestras lágrimas, que son nuestra agua continua, comprándola con la paga; pues pagamos para que nos maltraten, y para que llorar nos hagan. Compramos o los leños en que nos crucifiquen, o la leña con que nos quemen y consuman" (Loayza, 1948: 9-10). A primera vista, parece sorprendente que sus lágrimas sea el agua que beben con precio y que la leña sea para asesinarlos, cuando el agua quitada de los afligidos judíos era nada más que agua y la leña solamente era su madera para la cocina. Esencialmente, el cura manifiesta que el sufrimiento padecido por los indios y los judíos es mucho más profundo de lo que los versos del poema revelan a nivel superficial. Además, sugiere que los versos del poema no muestran la severidad total del sufrimiento de los judíos. Perdieron todo, pues el agua más cara que derramaron era las lágrimas y el sudor de la fatiga, mientras la leña les llevó a una muerte sin reposo ( $L m$., V, v.5).

Aparte de sus lágrimas y sudor en "copiosísimas cantidades", el agua que los indios compran con su labor es de la Iglesia para la administración de "las aguas puras de la Gracia". Aun así, los indios siguen "a secas y sedientos del Saber, entre los cienos y lodazales inmundos de la Ignorancia" (Loayza, 1948: 10). La Iglesia no ha cumplido con su responsabilidad de traerles a los indios el mensaje de luz y salvación, pues ha esclavizado a los ignorantes, 
para aprovecharse de su labor, no permitiéndoles elevarse con el intercambio de conocimiento. La Iglesia, así mismo, no ha permitido a los indios unirse a las órdenes religiosas ni asumir el sacerdocio en completa hermandad. Cada uno de los textos habla con su voz literal dentro de su limitado contexto histórico, entregando mensajes distintos de diferentes épocas socio-ideológicas que revelan "specific points of view on the world" (Bajtín, 1981: 291).

El lazo entre estas dos voces no es una conexión directa, donde un texto se iguala al otro, pues se mezclan para crear un dialogismo informativo y poético. El verso del poema bíblico sirve como modo de introducción a una queja del pueblo americano y también modula la manera en que Fray Calixto revela su protesta con la retórica que se emplea frecuentemente en un sermón. De igual modo, el texto bíblico es alterado por las palabras más modernas, ya que las palabras nuevas nos conducen a experimentar no solamente la experiencia indígena, sino también la experiencia judía con otro nivel de entendimiento. Así, pues, los dos textos modifican el significado del uno con respecto al otro, mientras el lector los aprecia con nuevo entendimiento y percepción. Borges (1960), el gran escritor argentino del siglo XX, expone esta misma idea en su ensayo "Kafka y sus precursores", donde afirma que un escritor crea sus propios predecesores, alterando el pasado. "El hecho es que cada escritor crea a sus precursores. Su labor modifica nuestra concepción del pasado, como ha de modificar el futuro" (148).

Escritores del pasado, presente y futuro sólo pueden ser considerados kafkianos después de Kafka, y por lo tanto, gracias a la existencia de Kafka y su obra, el pasado ha sido modificado. El poema de Lamentaciones, en similar sentido, es eternamente alterado después de leer la versión de Fray Calixto, pues le da significado adicional a la experiencia judía. Pueden percibirse en el poema las angustias de ambos pueblos, y por eso la interpretación del poema está basada en parte en la descripción que dejó el religioso. Justamente es a través de este juego entre ambos textos que se articula el tema de lamentación por los agravios cometidos y la esperanza de un cambio. Estos dos temas sirven como la motivación principal detrás de la creación de ambos textos.

El mensaje principal que abarca toda la "Representación verdadera" es el deseo de los indios y los mestizos de ser considerados como vasallos españoles con el mismo valor y con los mismos derechos que los españoles peninsulares. El humilde fraile escribe: "Conviene a saber: que los indios, vuestros vasallos, son iguales a vuestros vasallos españoles" (Loayza, 1948: 25). Los españoles peninsulares 
en el reino del Perú, sin embargo, no estaban de acuerdo, pues consideraban a los indios como seres inferiores, y la carta ofrece muchísimos ejemplos de la desigualdad impuesta sobre ellos. Las voces de la "Representación verdadera" se juntan para convencer al Rey de intervenir por el bienestar de los indígenas peruanos. Bajtín (1981) nos ilumina sobre la función de estas voces dentro de un texto como la novela: "A particular language in a novel is always a particular way of viewing the world, one that strives for a social significance" (333).

La forma en que estas voces se expresan demuestran su punto de vista y su deseo de alterar sus circunstancias sociales -por eso ofrecen lamentos tan penosos-. Quizás el lamento más dolorido es aquel donde el fraile solloza por los abusos que han soportado las humildes mujeres y doncellas vírgenes indígenas. Hablando con el pueblo peruano, Fray Calixto lamenta "ver a nuestras hijas hechas esclavas y siervas de las mujeres españolas, que siendo, como mujeres engreídas y como españolas, soberbias y altivas; porque creyéndose todas, señoras, es cada una, una reina para la miserable india, que la sirve más rendida y amante que una hija a su madre; y más abatida y maltratada que una esclava vil a su señora" (Loayza, 1948: 14). Solloza, así mismo, por el hecho de que se les prohíbe a los indios entrar a la vida religiosa, ya que los españoles prefieren explotar su labor.

Aunque los indios sirven a los españoles, a menudo, según Fray Calixto, tienen más limitaciones que los mismos esclavos negros. “¿Qué el negro esclavo se pueda libertar, y quede libre para irse donde quisiere, y pueda pasar a España; y el Indio, aún el noble, sea tributario y mitayo de nuestros siervos, y no tenga albedrío para libremente vivir donde le fuere conveniente, y no tenga modo de pasar a España a ver su Rey, y mostrarle sus heridas?" (12). Parece mentira que los negros tuvieran más derechos que los indios, pero así lo reafirma el desesperado fraile: "La Nación etiópica, negra, esclava, vil y sierva, en estas Indias, es nuestra Señora que nos maltrata y manda" (12). Loayza (1948) explica que los "indígenas peruanos en muchos casos eran esclavos de los esclavos negros" (12). Debido a su subvalorado puesto dentro de la sociedad, "los españoles que desde el principio los han tratado peores que a burros, y más abatidos que los mismos perros" (36). Para enmendar el deplorable estado del indio, la "Representación verdadera" pide que el Rey se vuelva hacia ellos y que lleve a los indios a España, donde pueden honrarle y mostrarle sus heridas (28). Ofrece para ello once remedios que el reino debe adoptar a fin de parar los extensos abusos. 
El significado de la "Representación verdadera" está encajado dentro de los límites establecidos por el poema encontrado de Lamentaciones. Las denuncias que se hacen dentro del documento sólo se dan a luz después de ser presentadas por sus correspondientes versículos de escritura. Dentro del discurso las voces trabajan juntas para pronunciar su mensaje lamentable desde el polvo. La combinación de las dos voces, la de la Biblia y la de los indios, es indicativa de la identidad del autor. Como hijo legítimo de un español y una princesa incaica, Fray Calixto mezcla dos discursos que representan sus dos identidades. Hábilmente combina las palabras de la Biblia y el antiguo mundo con las palabras de los indios y sus ancestros incas.

Mestizos e indios, Fray Calixto y sus colaboradores orquestan el discurso con doble voz dentro del contexto peruano y siguiendo el texto de Lamentaciones. Este tipo de situación es una construcción híbrida: es solamente un texto, pero contiene dos voces que implican: 'two speech manners, two styles, two 'languages,' two semantic and axiological belief systems" (Bajtín, 1981: 304). El uso del poema de Lamentaciones requiere que el autor de la "Representación verdadera" relacione o improvise una queja con cada versículo bíblico, y el documento no sale de esta construcción paralela hasta nombrar todas las quejas del pueblo peruano. Los temas de la carta exclamatoria salen a luz dentro de la diversidad de sus voces para demandar el tratamiento justo de los indios y los mestizos. Las voces de la obra ruegan por un cambio y apelan al rey como el único poder capaz de escucharlas.

\section{Bibliografía}

Bajtín, M. M., \& Holquist, M. (1981). The Dialogic Imagination: Four Essays. Austin, Texas: University of Texas Press.

Bernales Ballesteros, J. (1969). "Fray Calixto de San José Tupac Inca, procurador de indios y la 'Exclamación' reivindicacionista de 1750", Historia y cultura. Revista del Museo Nacional de Arqueología, Antropología e Historia del Perú, n 3, pp. 5-18.

Borges, J. L. (1960). Obras completas. Buenos Aires, Argentina: Emecé.

Dueañas, A. (2010). Indians and Mestizos in the Lettered City. Reshaping Justice, Social Hierarchy, and Political Culture in Colonial Peru. Colorado: University Press of Colorado.

Freedman, D. N. (1992). The Anchor Bible Dictionary, vol. 4. New York: Doubleday.

Kee, H. C. (1997). The Cambridge Companion to the Bible. New York: Cambridge University Press.

La Santa Biblia. Revisión de 1960. Reina, C., Valera, C., \& Broadman \& Holman Publishers, 1994. Nashville: Broadman \& Holman Publishers. 
Lienhard, M. (1992). Testimonios, cartas y manifiestos indígenas. Desde la conquista hasta comienzos del siglo XX. Caracas: Biblioteca Ayacucho.

Loayza, F. A., \& Chokewanka, J.D. (1948). Fray Calixto Túpak Inka, documentos originales $y$, en su mayoría, totalmente desconocidos, auténticos, de este apóstol indio, valiente defensor de su raza, desde el año de 1746 a 1760. Las doce dudas, códice del año de 1570, de autor anónimo. Lima: D. Miranda.

Myers, A. C. (1987). The Eerdmans Bible Dictionary. Grand Rapids, MI: Eerdmans.

Prieto de Zegarra, J. (1974). Mensajes precursores de la Independencia del Perú. Lima: Arica.

Steinmueller, J. E., \& Sullivan, K. (1956). Catholic Biblical Encyclopedia: Old Testament. New York: J. F. Wagner.

Vargas Ugarte, R. (1956). Historia del Perú. Virreinato (siglo xviii) 17001790. Lima: Librería e Imprenta Gil.

Walker, C. (2008). Shaky Colonialism: The 1746 Earthquake-Tsunami in Lima, Peru, and Its Long Aftermath. Durham: Duke University Press. 
